\section{About a painful wrist after a forced dorsiflexion trauma}

\section{CLINICAL INTRODUCTION}

A young adult without medical history was admitted a day following right wrist trauma. He fell from a height of three stairs with forced dorsiflexion of his wrist, and complained of severe pain and functional disability.

Clinical examination revealed a mildly swollen wrist with tenderness on dorsal palpation. Active and passive movements were impossible because of the pain. Anatomical snuffbox and scaphoid palpation was painless.

\section{QUESTION}

What is the diagnosis (figure 1)?
A. Isolated scaphoid fracture
B. Isolated capitate fracture
C. Fenton's syndrome
D. Wrist sprain

For the answer see page 413

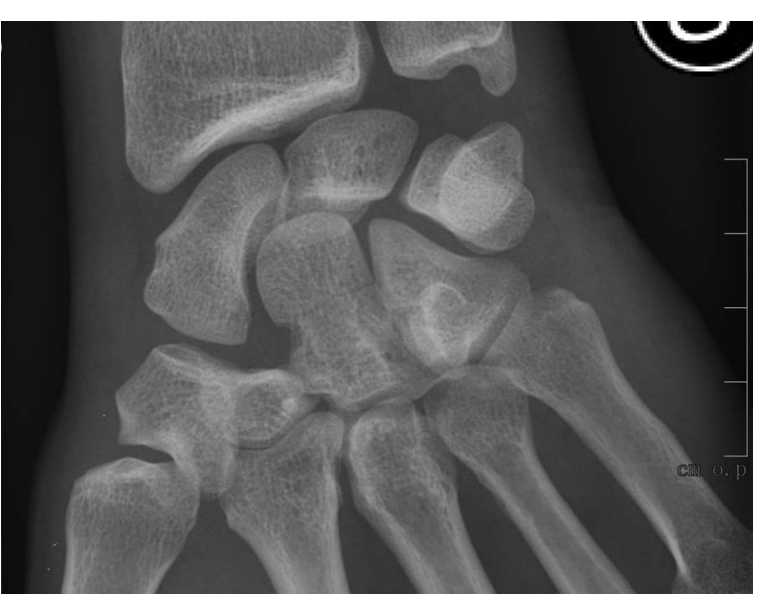

Figure 1 Right wrist face X-ray. 
IMAGE CHALLENGE

\section{About a painful wrist after a forced dorsiflexion trauma}

From the question on page 385.

\section{ANSWER: B}

Radiography shows a capitate fracture (figure 2). Capitate fracture is very rare, and in most of the cases, it is associated with scaphoid fracture, $180^{\circ}$ rotation of the capitate and periulnate dislocation (Fenton's syndrome ${ }^{1}$ ). Isolated capitate fractures constitute only $0.3 \%$ of wrist fractures. ${ }^{2}$

In the case of a capitate fracture, a CT scan is required in order to eliminate an associated lesion. In this case, fracture was isolated.

Wrist trauma with significant symptomatology and suspect physical examination or radiography should be explored by CT scan and needs specialised advice. Without a negative scan, a wrist sprain cannot be confirmed.

\section{Oscar Thabouillot, Didier Ollat}

Emergency Department, Bégin Military Hospital, Saint-Mandé, France

Correspondence to Dr Oscar Thabouillot, Emergency Department, Bégin Military Hospital, 69 avenue de Paris, 94160 Saint-Mandé, France; thabouillot@hotmail.com

Contributors OT wrote the text and examined and treated the patient. DO corrected the article and found the references.

Competing interests None.

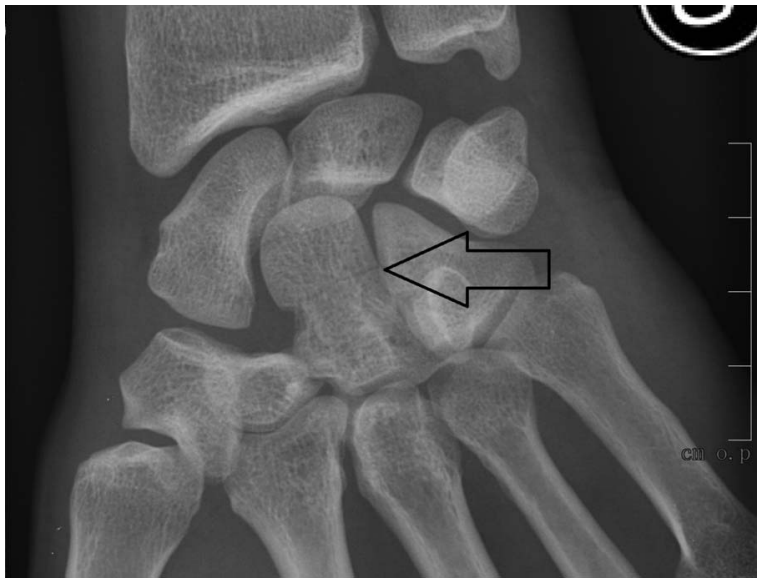

Figure 2 Right wrist face X-ray with marked capitate fracture.

Provenance and peer review Not commissioned; internally peer reviewed.

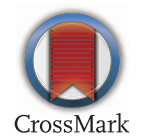

To cite Thabouillot O, Ollat D. Emerg Med J 2016;33:413.

Accepted 16 July 2015

Emerg Med J 2016;33:413. doi:10.1136/emermed-2015-204852

\section{REFERENCES}

1 Hamdi MF. The scaphocapitate fracture syndrome: report of a case and a review of the literature. Musculoskelet Surg 2012;96:223-6.

2 Rand JA, Linscheid RL, Dobyns JH. Capitate fracture: a long-term follow-up. Clin Orthop Relat Res 1982;165:209-16. 